\title{
Obez hastalarda pron pozisyonda PEEP uygulamasının solunum mekanikleri, intraabdominal basınç ve hemodinami üzerine etkileri
}

\author{
Effects of PEEP on respiratory mechanics, intraabdominal pressure and hemodynamics \\ during prone positioning in obese patients
}

İlknur Hatice Akbudak, İsmail Hakkı Akbudak, Hafize Öksüz

Gönderilme tarihi:28.08.2020

Kabul tarihi:24.09.2020

\begin{abstract}
Özet
Amaç: Amacımız pron pozisyonda cerrahi geçirecek obezlerde farklı seviyelerde ekspirasyon sonu pozitif basınç (PEEP) uygulamalarının solunum mekanikleri, hemodinami ve intraabdominal basınç üzerine etkilerini araştırmaktır.

Hastalar ve yöntem: Pron pozisyonda, batın dışı operasyon geçirecek olan, vücut kitle indeksi (VKI) 30 ve üzeri 54 hasta çalışmaya alındı. Hastalar 3 gruba randomize edildi. PEEP Grup 1'de $0 \mathrm{cmH}_{2} \mathrm{O}$, Grup 2'de $5 \mathrm{cmH}_{2} \mathrm{O}$, Grup 3'de $10 \mathrm{cmH}_{2} \mathrm{O}$ olarak ayarlandı. Pron çevirmeden hemen önce supin pozisyonunda ve pron pozisyonunda kan gazı örnekleri alındı. Kalp tepe atımı(KTA), sistolik arter basıncı(SAB), diastolik arter basıncı (DAB), ortalama arter basıncı $(\mathrm{OAB})$ ve dinamik kompliyans, Pozitif inspiratuar basınç (PIP), plato basınç (Pplato), solunum sonu karbondioksit basıncı $\left(\mathrm{PetCO}_{2}\right)$, oksijen saturasyonu $\left(\mathrm{SpO}_{2}\right)$, tidal volüm (VT) kaydedildi. İntrabdominal basınç ölçümü (IAB) yapıldı. Prondan supin pozisyonuna döndürüldükten sonra ölçümler tekrarlanarak kaydedildi.

Bulgular: Supin dönem ile karşılaştırıldığında pron dönemde ölçülen kompliyans, SAB, DAB, OAB, KTA, PetCO ${ }_{2}$ değerleri her üç grupta da istatistiksel olarak anlamlı düşük saptandı [p değeri sırasıyla; $(p=0,02)$, $(p=0,018),(p=0,013),(p=0,002),(p=0,02),(p=0,01)$. Supin dönem ile karşılaştırıldığında pron dönemde ölçülen PIP ve Pplato değerleri istatistiksel olarak anlamlı daha yüksek saptandı $(p=0,002)$ ve $(p=0,001)$. Gruplar arası ikili karşılaştırmada Grup 3'de PIP ve Pplato değerleri Grup 1'e göre anlamlı yüksek saptandı $(p=0,002)$ ve $(p=0,001)$.

Sonuç: Pron pozisyonda cerrahi girişim geçirecek hastalarda fizyolojik PEEP uygulamasının yararlı olacağı, özellikle VKi yüksek hastalarda pron pozisyonun intraabdominal basıncta anlamlı artışa sebep olmadığı ve hemodinamiyi olumsuz etkilmediği ayrıca fizyolojik sınırlarda PEEP uygulamasının oksijenlenmeyi iyileştirebileceği sonucuna varılmıştır.
\end{abstract}

Anahtar kelimeler: Pron pozisyon, obezite, solunum mekaniği, intrabdominal basınç, hemaodinami.

Akbudak ï, Akbudak ì, Öksüz H. Obez hastalarda pron pozisyonda PEEP uygulamasının solunum mekanikleri, intraabdominal basınç ve hemodinami üzerine etkileri. Pam Tıp Derg 2021;14:113-118.

\begin{abstract}
Purpose: The aim of our study was to investigate effects of end-expiratory positive pressure (PEEP) at varying degrees on respiratory mechanics, hemodynamic and intra-abdominal pressure in obese patients undergoing surgical intervention at prone position.

Materials and methods: The study included 54 patients with BMI (Body Mass Index) $\geq 30 \mathrm{~kg} / \mathrm{m}^{2}$ who were scheduled for extra-abdominal surgery at prone position. The patients were randomly assigned into 3 groups as follows: PEEP was set to $0 \mathrm{cmH}_{2} \mathrm{O}$ in group 1; $5 \mathrm{cmH}_{2} \mathrm{O}$ in group 2; and $10 \mathrm{cmH}_{2} \mathrm{O}$ in group 3. The blood gas sampling was performed at supine position immediately before placing patient to prone position and in the prone position. Heart rate (HR), systolic arterial pressure (SAP), diastolic arterial pressure (DAP), mean arterial pressure (MAP) dynamical compliance, peak inspiratory pressure $(P I P)$, plateu pressure $\left(P_{\text {plateu }}\right)$, end tidal carbondioxide pressure $\left(\mathrm{P}_{\mathrm{ETCO} 2}\right)$, oxygen saturation $\left(\mathrm{SpO}_{2}\right)$, tidal volume $(\mathrm{VT})$ were recorded. Simultaneously, intra-abdominal pressure was measured. Measurements were repeated after patient placed into supine position from prone position.

Results: When compared to supine period, compliance, SAP, DAP, MAP, HR and $P_{\mathrm{ETCO} 2}$ values measured at prone period were found to be significantly higher in all groups $(p=0,02),(p=0,018),(p=0,013),(p=0,002)$, $(p=0,02),(p=0,01)$, respectively) When compared to supine period, PIP and $\mathrm{P}_{\text {plateu }}$ values measured at prone period were found to be significantly higher $(p=0,002)$ and $(p=0,001)$, respectively). In binary comparisons, PIP and $\mathrm{P}_{\text {plateu }}$ values were found to be significantly higher in group 3 than group $1(p=0,002)$ and $(p=0,001$, respectively).
\end{abstract}

İlknur Hatice Akbudak, Dr. Öğr. Üye. Pamukkale Üniversitesi Tıp Fakültesi Anesteziyoloji ve Reanimasyon Anabilim Dalı, Denizli, Türkiye, e-posta: ilhakbudak@gmail.com (orcid.org/0000-0001-9937-9169) (Sorumlu Yazar)

İsmail Hakkı Akbudak, Dr. Öğr. Üye. Pamukkale Üniversitesi Tıp Fakültesi İç Hastalıkları Anabilim Dalı, Yoğun Bakım Bilim Dalı, Denizli, Türkiye, e-posta: ishakbudak@gmail.com (orcid.org/0000-0002-3716-9243)

Hafize Öksüz, Prof. Dr. Kahramanmaraş Sütçü İmam Üniversitesi Tıp Fakültesi, Anesteziyoloji ve Reanimasyon Anabilim Dalı, Kahramanmaraş, Türkiye, e-posta: drhoksuz@hotmail.com (orcid.org/0000-0001-5963-6861) 
Conclusion: It was concluded that physiological PEEP administration will be beneficial in patients undergoing surgery at prone position; that it did not cause significant increase in intra-abdominal pressure and negatively affect hemodynamic, particularly in patients with high BMI; and that PEEP in physiological range improved oxygenation.

Key words: Prone position, obesity, respiratory mechanics, intra-abdominal pressure, hemodynamic.

Akbudak $\mathrm{IH}$, Akbudak $\mathrm{IH}$, Oksüz $\mathrm{H}$. Effects of PEEP on respiratory mechanics, intraabdominal pressure and hemodynamics during prone positioning in obese patients. Pam Med J 2021;14:113-118.

\section{Giriş}

Ekspiryum sonu pozitif basınç uygulaması, alveolü açık tutar, her solukta alveolun açılıp kapanmasını engelleyerek absorbsiyon atelektazisinin önüne geçer. Fonksiyonel rezidüel kapasiteyi (FRK) arttırarak oksijenizasyonu iyileştirir, V/Q oranını düzeltir, intrapulmoner şantı azaltır [1, 2].

Pron pozisyon diafragma üzerindeki basıncı azaltaraksupin pozisyonunda kapanma eğiliminde olan alveollerin açık kalmasını sağlar $[3,4]$. Yapılan çalışmalarda pron pozisyonda akciğerlerin dorsal bölgelerinin daha iyi havalandığı ve oksijenizasyonun düzeldiği gösterilmiştir. $\mathrm{Bu}$ durum genel anestezi ile FRK'sı azalan hastalarda solunum mekaniklerini iyileştirmektedir. Ancak pron pozisyon ile gelişebilecek sorunlara da dikkat etmek gerekir. Toraks üzerine gövdenin ağırlığının binmesi, solunumsal mekanikler olumsuz etkileyebilmektedir. Vücut ağırlığının karın duvarına yüklenmesi sonucu; batın içi basınç, hava yolu direnci ve göğüs duvarı rezistansı artabilir. Bu durumda doğru pozisyon vermek, abdomeni uygun şekilde serbest hale getirmek önem kazanmaktadır. Gelişebilecek sorunları giderebilmek için omuz ve pelvis hizasına yastık yerleştirilerek, karnın serbest hareketi sağlanır, Pron pozisyonu, cerrahi endikasyonlar dışında, akut solunum yetmezliği tedavisinde deoksijenizasyonu ve ventilasyon/perfüzyon ilişkisini iyileştirmek için de kullanılmaktadır [5].

Obezite; vücut kitle indeksinin (VKI) 30 ve üzeri olma durumudur [6]. Obezite; toraks ve abdomende yağ dokusundaki artışa bağlı olarak, akciğer, göğüs duvarı ve diafragma arasındaki karşılıklı etkileşimle belirlenen solunum mekaniğini ve akciğer volümlerini olumsuz etkiler. Ayrıca intraabdominal basıncı artıran bir durumdur [7], bu nedenle obez hastalarda pron pozisyonda solunum parametrelerindeki değişiklikler daha belirgin olur [7].
Yapılan bu çalışmada; pron pozisyonda opere edilecek obez hastaların, bu pozisyonda uygulanacak farklı seviyelerde PEEP değerlerinin hemodinami, solunum parametreleri ve intraabdominal basınç üzerine etkilerini incelemeyi amaçladık.

\section{Gereç ve yöntem}

$\mathrm{Bu}$ prospektif çalışma Kahramanmaraş Sütçü İmam Üniversitesi Tıp Fakültesi Araştırma ve Uygulama Hastanesi Etik Kurulu onayı alındıktan sonra, batın dışınedenlerle operasyon geçirecek VKI 30 ve üstü olan 54 hasta üzerinde gerçekleştirildi.

Çalışmaya, gönüllü olmayı kabul eden, onamı alınmış, ASA I-II grubu, 18-65 yaş arasında, daha önce bilinen diyabetes mellitus veya kardiyo pulmoner hastalığı bulunmayan hastalar dahil edildi. Tüm hastalar operasyondan bir gün önce görülerek preanestezik değerlendirmeleri yapıldı.

Daha önce toraks veya abdominal operasyon geçirmiş olan hastalar çalışma dışı bırakıldı. Hastalara ameliyat öncesi premedikasyon uygulanmadı.

Anestezi indüksiyonu iv $1 \mathrm{mcg} / \mathrm{kg}$ fentanyl, $5 \mathrm{mg} / \mathrm{kg}$ pentotal, $0,6 \mathrm{mg} / \mathrm{kg}$ rokuronyum ile sağlandı. İç çapı 7,5-8,0 mm olan spiralli tüp ile endotrakeal entübasyon yapıldı. Hastaların ventilasyonu Dräger Primus $\AA$ marka (Lübeck, Almanya) mekanik ventilatörün SIMV volüm kontrol modunda 4 L.dk akımda $\% 60$ N2O $\% 40 \mathrm{O}_{2}$, ve sevoflurane 1,0 MAC ile sağlandı. Solunum sayısı 12 soluk/dk, inspirasyon ekspirasyon oranı 1:2, tidal volüm $8 \mathrm{ml} / \mathrm{kg}$ olacak şekilde ayarlandı.

Hastalar randomize olarak, PEEP uygulanmayan (Grup 1), $5 \mathrm{cmH}_{2} \mathrm{O}$ PEEP uygulanan (Grup 2) ve $10 \mathrm{cmH}_{2} \mathrm{O}$ PEEP uygulanan (Grup 3) diye üç gruba ayrıldı. 
İlk ölçümler; indüksiyondan önce supin pozisyonda, ikinciölçümler; indüksiyondan sonra supin dönem 10. dk'da, üçüncü ölçümler; prona çevirmeden hemen önce supin pozisyonda, diğer ölçümler ise pron pozisyonundan sonra 15. dk, 30. dk, 45. dk, 60. dk, 75. dk ve 90. dk ile operasyon bitiminde prondan supin pozisyonuna döndürüldükten sonra 10. dk.'da kaydedildi.

Vital parametreler olarak; sistolik ve diyastolik kan basıncı (SAB, DAB), ortalama arter basıncı $(\mathrm{OAB})$, kalp tepe atımı (KTA), solunum parametreleri olarak; dinamik kompliyans, tidal volüm (VT), tepe inspiratuvar basınç (PIP), plato basıncı (Pplato), endtidal karbondioksit basıncı $\left(\mathrm{PetCO}_{2}\right)$, oksijen satürasyonu $\left(\mathrm{SpO}_{2}\right)$ kaydedildi. Arteriyel kan gazı örnekleri alınarak $\mathrm{Ph}, \mathrm{PaCO}_{2}, \mathrm{PaO}_{2}$, kayıt edildi. Alınan kan gazı örnekleri Radiometer ABL 70 marka cihaz ile değerlendirildi. Hasta takibi Siemens SC 7000 monitör ile yapıldı. Eş zamanlı olarak üretral mesane kateteri kullanılarak; revize edilmiş Cheatham aralıklı ölçüm tekniği ile IAB (intrabdominal basınç) ölçümü yapıldı. Operasyon süresince yapılan diğer ilaçlar ve gelişen komplikasyonlar kaydedildi.

İstatistiksel analizler, SPSS versiyon 17 yazılımı kullanılarak yapıldı. Tanımlayıcı analizlerin (ortalama, standart sapma) yanı sıra değişkenlerin normal dağılıma uygunluğu, Kolmogorov-Smirnov/Shapiro Wilktestleri kullanılarak incelendi. Normal dağılıma uyan değişkenlerin gruplara göre farklılığı Anova testi ile, uymayan değişkenlerin gruplara göre farklılığı Kruskal Wallis testi ile değerlendirildi. İkişerli karşılaştırmalarda Mann-Whitney U testi kullanıldı. Zamanla değişen değişkenler, tekrarlı ölçümler varyans analizi kullanılarak incelendi.
Sonuçlarda, anlamlılık $p<0,05$ düzeyi olarak değerlendirildi.

\section{Bulgular}

Gruplar arasında anestezi süreleri, VKI, yaş ve cinsiyet dağılımı açısından istatistiksel olarak anlamlı bir fark yoktu $(p>0,05)$ (Tablo 1$)$.

Grupların supin ve pron dönemde ölçülen parametre sonuçları Tablo 2'de verilmiştir.

Supin dönem ile karşılaştırıldığında pron dönemde ölçülen kompliyans, SAB, DAB, $\mathrm{OAB}, \mathrm{KTA}, \mathrm{PetCO}_{2}$ değerleri her üç grupta da istatistiksel olarak anlamlı düşük saptandı. $P$ değeri sırasıyla; $(p=0,02),(p=0,018),(p=0,013)$, $(p=0,002),(p=0,02),(p=0,01)$.

Grup içi ikili karşılatırmada SAB, KTA, $\mathrm{PetCO}_{2}$ ve compliyans değişkenleri açısından süreç boyunca gruplar arasında anlamlı fark saptanmadı $\quad(p=0,12), \quad(p=0,59), \quad(p=0,26)$, $(p=0,21)$.

Supin dönem ile karşılaştırıldığında pron dönemde ölçülen PIP ve P plato değerleri istatistiksel olarak anlamlı daha yüksek saptandı $(p=0,002),(p=0,001)$.

Grup içi ikili karşılaştırmada P plato ve PIP değeri Grup 3'de, Grup 1'e göre anlamlı yüksek seyretti $(p=0,001),(p=0,002)$.

Supin dönem ile karşılaştırıldığında pron dönemde İAB değerlerinde $(p=0,38)$ ve kan gazında ölçülen $\mathrm{Ph}, \mathrm{pO}_{2}$ ve $\mathrm{SpO}_{2}$ değişkenlerinde anlamlı farklılık saptanmadı $(p=0,23),(p=0,81)$, $(p=0,93)$.

Tablo 1. Demografik veriler ve anestezi süreleri (Ortalama $\pm S D$ )

\begin{tabular}{lllll}
\hline & Grup 1 & Grup 2 & Grup 3 & p değeri \\
\hline Cinsiyet (Erkek/Kadın) & $9 / 9$ & $7 / 11$ & $12 / 6$ & 0,43 \\
Yaşortalaması (yıl) & $47,8(13,0)$ & $55,2(10,4)$ & $51,9(13,2)$ & 0,19 \\
Süre (dakika) & $105,11 \pm 15$ & $112,19 \pm 18$ & $108,12 \pm 11$ & 0,56 \\
VKi (kg/m 2$)$ & $31,6 \pm 0,4$ & $30,9 \pm 0,34$ & $31,7 \pm 0,4$ & 0,87 \\
\hline
\end{tabular}

PEEP: Ekspirasyon sonu pozitif basınç, VKI: Vücut kitle indeksi 
Tablo 2. Grupların supin ve pron dönemde ölçülen değerleri

\begin{tabular}{|c|c|c|c|c|c|c|}
\hline & GRUP 1 & (PEEP 0) & GRUP2 & (PEEP 5) & GRUP3 & (PEEP 10) \\
\hline & SUPIN & PRON & SUPIN & PRON & SUPIN & PRON \\
\hline $\mathrm{SAB}(\mathrm{mmHg})$ & 112,8 & 105,6 & 120,7 & 109,1 & 123,1 & 121,4 \\
\hline $\mathrm{DAB}(\mathrm{mmHg})$ & 67,6 & 66,7 & 75,8 & 72,1 & 72,4 & 77,5 \\
\hline $\mathrm{OAB}(\mathrm{mmHg})$ & 82,3 & 80,3 & 92,3 & 84,7 & 89,2 & 93,4 \\
\hline KTA (dk) & 78,4 & 75 & 82,8 & 72 & 80,5 & 78,7 \\
\hline $\mathrm{PetCO}_{2}(\mathrm{mmHg})$ & 33,7 & 30,8 & 32,2 & 30,8 & 33,2 & 30,2 \\
\hline IAB $(\mathrm{mmHg})$ & 14,9 & 18,5 & 17,5 & 20 & 17,1 & 22,1 \\
\hline $\mathrm{PIP}\left(\mathrm{cmH}_{2} \mathrm{O}\right)$ & 17,0 & 20 & 20,1 & 23,6 & 22,3 & 25,9 \\
\hline Pplato $\left(\mathrm{cmH}_{2} \mathrm{O}\right)$ & 15,5 & 18,5 & 18,2 & 21,7 & 19,8 & 24,5 \\
\hline $\mathrm{Cs}\left(\mathrm{ml} / \mathrm{cmH}_{2} \mathrm{O}\right)$ & 51,9 & 38,3 & 48,6 & 36,6 & 42,8 & 34,2 \\
\hline $\mathrm{pH}$ & 7,41 & 7,43 & 7,42 & 7,43 & 7,42 & 7,44 \\
\hline $\mathrm{PaCO}_{2}(\mathrm{mmHg})$ & 37,7 & 39,9 & 33,9 & 33,3 & 33,3 & 32,3 \\
\hline $\mathrm{PaO} 2(\mathrm{mmHg})$ & 167,3 & 192,3 & 186,6 & 212,3 & 198,5 & 256,7 \\
\hline $\mathrm{SpO}_{2}(\%)$ & 98,3 & 98,6 & 98,5 & 99,2 & 98,7 & 99,8 \\
\hline
\end{tabular}

KTA: Kalp tepe atımı, SAB: Sistolik arte rbasıncı, DAB: Diastolik arter basıncı,

OAB: Ortalama arter basıncı, Cs: Dinamik kompliyans, PIP: Pozitifin spiratuar basınç,

Pplato: plato basınç, $\mathrm{PetCO}_{2}$ : Solunum sonu karbondioksit basıncı,

$\mathrm{SpO}_{2}$ : Oksijen saturasyonu, VT: Tidal volüm, IAB: İntrabdominal basınç ölçümü

\section{Tartışma}

Pron pozisyonda cerrahi girişim geçirecek obez hastalarda farklı seviyelerde PEEP uygulamalarının solunum mekanikleri, hemodinami ve intraabdominal basınç üzerindeki etkilerini araştırmayı amaçladığımız bu çalışmada; PEEP'in hemodinamik sistem üzerine etkisinin minimal düzeyde olduğu; $S A B$, DAB, OAB ve KTA hızında azalmaya yol açtığı, bu azalmanın da normal klinik sınırlar içerisinde kaldığı görülmüştür. Ayrıca olgularda pron pozisyon süreci içinde PEEP uygulaması ile istatistiksel olarak anlamlı bir IAB artışı olmadığı ve hemodinaminin olumsuz etkilenmediği tespit edilmiştir.
Pron pozisyonda $10 \quad \mathrm{cmH}_{2} \mathrm{O}$ PEEP uygulanması hemodinamide tedavi gerektirecek değişiklikler yapmadan $\mathrm{PaO}_{2}$ 'de artışa yol açmıştır ancak bu farkın istastistiksel olarak anlamlıolmadığıtespitedilmiştir.Pelosiveark.'nın [8] yaptığı çalışmada pron pozisyonun obez ve sağlıklı gönüllülerde göğüs duvarı ve akciğer kompliyansını etkilemeden oksijenizasyonu düzelttiği öne sürülmüştür. Kim ve ark. [9] benzer dizaynla yaptıkları çalışmalarında 5-10 $\mathrm{cmH}_{2} \mathrm{O}$ PEEP uygulamasının $0 \mathrm{cmH}_{2} \mathrm{O}$ PEEP'e oranla $\mathrm{PaO}_{2}$ üzerinde daha fazla artışa yol açtığını ve atelektaziyi önlediğini bildirmişlerdir. Bizim çalışmamızda $\mathrm{PaO}_{2}$ değerindeki artışta gruplar arasında anlamlı bir fark görülmemiştir.

PEEP'in hemodinamik etkileri hasta grubuna göre farklılıklar gösterebilmektedir. Wu CY ark. 
[4] yaptığı çalışmada Pron pozisyonun OKB ve kalp atım hızını belirgin olarak değiştirmezken kardiyak debiyi düşürdüğü gösterilmiştir. Çalışmamızda pozisyon değişikliği ile $S A B$, DAB, OAB, KTA'de İstastiksel olarak anlamlı bir düşüşe neden olmuştur. Ancak hiçbir olguda tedavi gerektirir hipotansiyon gözlenmemiştir.

Çalışmamızın temel bulgusu, pron pozisyonda ve farklı seviyelerde peep uygulamasında PIP ve $P$ plato değerlerinin artığı, İAB değerinde ise anlamlı bir değişiklik oluşmadığıdır. Literatür tarandığında; ilk olarak Sussman ve ark. [10] PEEP'in IAB üzerine etkisi incelemişler, PEEP uygulanmasının IAB üzerine anlamlı bir etkisi olmadığını göstermişlerdir. Ferrer ve ark. [11] ise PEEP uygulaması ile IAB artışı tespit etmişlerdir. Verzilli ve ark. [12] ARDS'li yoğun bakım hastasındaki çalışmalarında $15 \mathrm{~cm}$ H2O'dan yüksek PEEP uygulamasının IAB yükseldiğini göstermişlerdir. Heirng ve ark. [13] yaptıkları bir çalışmada ARDS'li hastalarda pronpozisyon uygulamasının IAB'de çok az bir artışa neden olduğunu tespit etmişlerdir. Çorman Dinçer ve ark. [14] yaptığı çalışmada PEEP 10 grubunda PIP değerinin pron dönemde supin döneme göre daha yüksek olduğunu göstermişlerdir.

Pozisyon verilirken hangi yöntem seçilirse seçilsin amaç abdominal basıncı minimale indirgemektir. Karın basıncını takip etmenin, özellikle obez hastalarda ventilatör parametrelerinin optimize edilmesine de yardımı olacaktır [15]. İntraabdominal basınç seviyeleri ile vücut kitle indeksi arasında yakın bir pozitif korelasyon vardır. Obez hastalarda supin pozisyonda dahi abdominal distansiyon ile $\mathrm{PaO}_{2}$ azalma görülür. Mekanik ventilasyon sırasında peep ve yüksek tidal hacimlerin kullanılması da intraabdominal basıncın yükselmesine neden olabilir, bu riski azaltmanın olası bir yolu düşük PEEP değerlerini kullanmakveayrıca ventilasyon parametrelerimizi ayarlamak için düşük hacimleri kullanmak olacaktır. Çalışmamızda fizyolojik sınırlarda peep kullanımının (grup 2 ve 3 ) İAB'| bir miktar artıdığı ancak peep kullanılmayan grup ile arasında istatistiksel olarak anlamlı bir fark oluşmadığı gösterilmiştir. Bulgular 10 $\mathrm{cmH}_{2} \mathrm{O}$ PEEP düzeyinin bizim hastalarımızda overdistansiyona ve ölü boşluk ventilasyonuna neden olmadığını göstermektedir.

$\mathrm{Bu}$ çalışmada supin pozisyona göre, pron pozisyonda compliyans değerinin düştüğü gözlenmiştir $(p=0,02)$. Pron dönemi PEEP0, PEEP5 ve PEEP10 grupları arasında kompliyans değerleri açısından anlamlı fark izlenmemiştir $(p=0,7)$. Pron pozisyonu ile static kompliyansın arttığı ama göğüs duvarı kompliyansını düştüğü, sonuç olarak da respiratuar system kompliyansının değişebileceği kanaatindeyiz. Lynch ve ark. [16] çalışmalarında pronpozisyonuna dönme ile birlikte kompliyansta \%30-35 düşüş ve hava yolu basıncında yükselme tespit etmişlerdir. Qui ve ark. [1] farklı PEEP seviyelerinde $\left(5,10,15 \mathrm{~cm} \mathrm{H}_{2} \mathrm{O}\right)$ recruite olan akciğer volümlerini araştırdıkları çalışmada VT sabit olması koşuluyla değişik PEEP düzeylerinde compliyans değerleri arasında belirgin fark gözlememişlerdir. Bu sonuçlar bizim çalışmamızla uyumludur.

Sonuç olarak; Pron pozisyonda cerrahi girişim geçirecek hastalarda fizyolojik peep uygulamasının; hemodinamik açıdan ve anlamlı intraabdominal basınç artışı açısından olumsuz etkisi saptanmamıştır, oksijenizasyon açısından uygulamanın yararlı olacağı kanısına varıımıştır.

Çıkar ilişkisi: Yazarlar çıkar ilişkisi olmadığını beyan eder.

\section{Kaynaklar}

1. Qiu HB, Xu HY, Yang Y, Zhou SX, Chen YM, Sun HM. Effects of positive end-expiratory pressure on lung recruited volume and oxygenation in patients with acute respiratory distress syndrome. Zhongguo Wei Zhong Bing Ji Jiu Yi Xue 2004;16:399-402.

2. Lee WL, Downey GP. Leukocyte elastase: physiological functions and role in acute lung injury. Am J Respir Crit Care Med 2001;164:896-904. https://doi.org/10.1164/ ajrccm.164.5.2103040

3. Mancebo J, Fernandez R, Blanch L, et al. A multicenter trial of prolonged prone ventilation in severe acute respiratory distress syndrome. Am J Respir Crit Care Med 2006;173:1233-1239. https://doi.org/10.1164/ rccm.200503-3530C

4. Wu CY, Lee TS, Chan KC, Jeng CS, Cheng YJ. Does targeted pre-load optimisation by stroke volume variation attenuate a reduction in cardiac output in the prone position. Anaesthesia 2012;67:760-764. https:// doi.org/10.1111/j.1365-2044.2012.07116.x

5. Soo Hoo GW. In prone ventilation, one good turn deserves another. N Engl J Med 2013;368:2227-2228. https://doi.org/10.1056/NEJMe1304349

6. Blaser AR, Parm P, Kitus R, Starkopf. Risk factors for intra-abdominal hypertension in mechanically ventilated patients. Acta Anaesthesiol Scand, 2011;55:607-614. https://doi.org/10.1111/j.1399-6576.2011.02415 
7. Damia G, Mascheroni D, Croci M, Tarenzi L. Perioperative changes in functional residual capacity in morbidly obese patients. Br J Anaesth 1988;60:574-578. https:// doi.org/10.1093/bja/60.5.574

8. Pelosi P, Caironi P, Taccone P, Brazzi L. Pathophysiology of prone positioning in the healthy lung and in ALI/ ARDS. Minerva Anestesiol 2001;67:238-247.

9. Kim KS, Park SS, Lim DG. The effects of preventive PEEP on perioperative pulmonary functions in patients receiving gastrectomy with a kent retractor. Korean J Anesthesiol 2003;45:359-364. https://doi.org/10.4097/ kjae.2003.45.3.359

10. Sussman AM, Boyd CR, Williams JS, DiBenedetto RJ. Effect of positive end-expiratory pressure on intraabdominal pressure. South Med J 1991;84:697-700. https://doi.org/10.1097/00007611-199106000-00006

11. Ferrer CPE, Molina E. Higher PEEP levels result in small increases in intraabdominal pressure in critical care patients. Intensive Care Med 2008;34:140.

12. Verzilli $D$, Constantin JM, Sebbane M, et al. Positive endexpiratory pressure affects the value of intra-abdominal pressure in acute lung injury/acute respiratory distress syndrome patients: a pilot study. Critical Care 2010;14:137. https://doi.org/10.1186/cc9193

13. Hering $R$, Wrigge $H$, Vorwerk $R$, et al. The effects of prone positioning on intraabdominal pressure and cardiovascular and renal function in patients with acute lung injury. Anesth Analg 2001;92:1226-1231. https:// doi.org/10.1097/00000539-200105000-00027

14. Çorman Dinçer P, Ünsel M, Yumru C. Pron pozisyonda PEEP uygulamasının solunum mekaniği ve arteriyel oksijenizasyon üzerine etkileri. Marmara Medical J 2013;26:146-150. https://doi.org/10.5472/ MMJ.2013.03034.1

15. Puiac C, Szederjesi J, Lazar A, Almasy E, Rad P, Puscasiu L. Influence of ventilation parameters on intraabdominal pressure. J Crit Care Med 2016;2:8084. https://doi.org/10.1515/jccm-2016-0016

16. Lynch S, Brand L, Levy A. Changes in Lung-Thorax compliance during orthopedic surgery. Anesthesiology 1959;20:278-282. https://doi.org/10.1097/00000542195905000-00004

Etik onayı: Kahramanmaraş Sütçü İmam Üniversitesi Tıp FakültesiAraştırma ve Uygulama Hastanesi Etik Kurulu'ndan 23.02.2012 tarih ve 2012/06 oturumunda 8 nolu onay alınmıştır.

\section{Yazarların makaleye olan katkıları}

İ.H.A. ve H.Ö. makalenin konseptini hazırlamıştır. İ.H.A. tarafından literatür taraması ve edinilen bilgilerin yorumlanması yapılmıştır. Makale İ.H.A. ve İ.H.A. tarafından yazıımıştır. H.Ö. gözden geçirip gerekli düzeltmeleri yapmıştır. Ayrıca tüm yazarlar makalenin tamamını tartışmış ve son halini onaylamıştır. 